\title{
Autochthonous Outbreak of Cutaneous Leishmaniasis due to Leishmania infantum in Corrientes Province, Argentina
}

\author{
Lucrecia Acosta-Soto, ${ }^{1} \dagger$ Ernesto Sebastian Encinas, ${ }^{2} \dagger$ Enrique-Jorge Deschutter, ${ }^{3}$ Roque-Antonio-Luis Pasetto, ${ }^{4}$ \\ Elisa-Maria-Angela Petri-de-Odriozola, ${ }^{4}$ Fernando-Jorge Bornay-Llinares, ${ }^{1}$ and José-Manuel Ramos-Rincón ${ }^{5 *}$ \\ ${ }^{1}$ Parasitology Area, Universidad Miguel Hernández de Elche, Alicante, Spain; ${ }^{2}$ Clinical Bacteriology Service, Hospital Angela Llano, Corrientes, \\ Argentina; ${ }^{3}$ Microbiology Department, Facultad de Ciencias Exactas, Químicas y Naturales de La Universidad Nacional de Misiones, Misiones, \\ Argentina; ${ }^{4}$ Dermatology Area, Dispensario Dermatologico Hersilia Casares de Blaquier, Corrientes, Argentina; ${ }^{5}$ Clinical Medicine Department, \\ Universidad Miguel Hernández de Elche, Alicante, Spain
}

\begin{abstract}
Endemic cutaneous leishmaniasis $(\mathrm{CL})$ in northern Argentina has traditionally been caused by Leishmania braziliensis. This study aims to describe an outbreak of Leishmania infantum-caused human CL in the Department Capital of Corrientes Province, Argentina. We retrospectively analyzed the reported cases of CL in this area from May 2015 to December 2016. Eighty cases of CL were clinically and analytically diagnosed, and there was one case of visceral leishmaniasis in a boy who also had CL. Patients' median age was 33.6 years (range 1-89 years), and 18.5\% were younger than 15 years; the male:female ratio was 3.5:1. Cases lived mostly in the municipality of Corrientes $(72.8 \%)$, whereas $27.2 \%$ resided in Riachuelo. Although $67.9 \%$ had a single lesion, $32.1 \%$ had several. Molecular analyses showed that L. infantum was the causative species in all cases. Our results show that for the first time, there was an outbreak of CL by L. infantum in an urban area of Argentina.
\end{abstract}

\section{INTRODUCTION}

Leishmaniasis is a vector-borne disease, caused by protozoa of the genus Leishmania and transmitted via sand flies from the Phlebotominae family. There are three clinical forms: mucocutaneous leishmaniasis, cutaneous leishmaniasis (CL), and visceral leishmaniasis (VL). ${ }^{1}$ In Argentina, the first recorded cases of CL date back to 1910 and originated in the northern part of the country. The disease reemerged around 1985, generating epidemic sites with 1,000 notified cases or more. ${ }^{2}$ Cutaneous leishmaniasis is mainly endemic to not only the province of Salta but also to Jujuy, Tucumán, Santiago del Estero, Chaco, Formosa, Misiones, and Corrientes. ${ }^{3-6}$

Four species causing human $\mathrm{CL}$ in Argentina have been isolated and identified, including three from the Vianna subgenus. In the order of importance, the species are Leishmanias (subgen. Vianna) braziliensis, Leishmania (subgen. Vianna) guyanensis, Leishmania (subgen. Leishmania) amazonensis, and most recently, Leishmania (subgen. Vianna) panamensis. ${ }^{7-10}$ No cases of CL caused by Leishmania infantum have yet been described in Argentina, albeit there have been a few cases of VL-the first in Misiones in 2006. ${ }^{2}$ Following this initial report, there have been others in the same province in canines, ${ }^{11,12}$ as well as in humans. ${ }^{13}$ Since then, the species has also been identified as the cause of VL in another four provinces: Salta, Entre Ríos, Santa Fé, and Santiago del Estero. ${ }^{14-16}$

Thus, $L$. infantum is present in Argentina as a cause of VL. This study describes the clinical and parasitological characteristics of the first $L$. infantum-caused CL outbreak in Argentina. This new clinical and epidemiological situation around $\mathrm{CL}$ in Argentina could also occur in environmentally similar contexts in South America.

\footnotetext{
*Address correspondence to José-Manuel Ramos-Rincón, Clinical Medicine Department, University Miguel Hernández de Elche, Ctra N-332, 03550 Sant Joan d'Alacant, Alicante 03010, Spain. E-mails: jose.ramosr@goumh.umh.es or jose.ramos@umh.es

†These authors contributed equally to this work.
}

\section{MATERIAL AND METHODS}

Patients. Patients $(N=81)$ were diagnosed with leishmaniasis in the Dermatological Dispensary Hersilia Cásares de Blaquier, which operates under the authority of the Corrientes Province Ministry of Health and is located in the municipality of Corrientes (coordinates: $\left.27^{\circ} 29^{\prime} 00^{\prime \prime} S 58^{\circ} 49^{\prime} 00^{\prime \prime} \mathrm{O}\right)$. The dermatological clinic is the only service that provides medical and laboratory care by specialists (dermatologists and microbiologists) to patients with a clinical presentation compatible with $\mathrm{CL}$ in the study project area and in Corrientes Province. Specifically, the dispensary provides care to patients within the public healthcare subsystem of this region of the country. Its clinic has a microbiological laboratory where parasitological and/or serological tests are performed as appropriate to the suspected diagnosis of each patient. All patients whose cases are reported in the surveillance system of Corrientes are referred for care for $\mathrm{CL}$ in the dermatological clinic. Patients were referred for dermatological examination in the dispensary by their primary care physicians from May 1, 2015 to December 31, 2016, in the municipalities of Corrientes (pop. 352,646) and Ria-

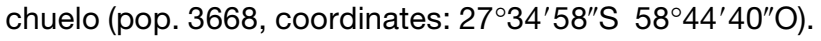

Diagnosis. Clinical suspicion of leishmaniasis was based on the presence of compatible lesions and patients' clinicoepidemiological characteristics, as assessed by primary care physicians. In the dermatological clinic, the information referred by the primary care physician and the medical history prepared by the clinic's specialists, who also complete the surveillance records, as mandated by the national and provincial reporting system for cases of leishmaniasis are evaluated. Of the 81 patients infected during the outbreak, 80 were diagnosed based on direct swabs of tissue taken from the lesions, whereas bone marrow aspirate and serological studies via immunochromatography were used in the remaining patient.

Parasitological diagnosis. Dermal scrapings were obtained from the inner border of the lesions and stained using the MayGrünwald-Giemsa method. ${ }^{17}$ Diagnosis was performed by direct observation of amastigotes in the stained slide smears 
of aspirates. Each slide was assessed for the presence of Leishmania spp. amastigotes using an optical microscope $(\times 1000)$ for 40 minutes per 100 fields.

Molecular analyses. Molecular confirmation was undertaken for the 28 patients (34.5\%) for whom a histological sample was available, with DNA extracted from the smear. Slides were submerged in xylol for 15 minutes and air-dried to remove the oil remaining from the immersion. A lysis buffer (provided in the extraction kit) was then added to the slide in aliquots of $50 \mu \mathrm{L}$; the tip of the dropper was used to scrape the surface and recover the liquid in a 1.5-mL Eppendorf pipette. Drawing from a total volume of lysis buffer of $200 \mu \mathrm{L}$ (four aliquots of $50 \mu \mathrm{L}+$ smear tissue), the extraction and precipitation of nucleic acid were performed using the Real Spin kit, according to the manufacturer's instructions (Ref: RMEGS01; Durviz s.I., Valencia, Spain). The DNA was eluted in a final volume of $100 \mu \mathrm{L}$.

Parasite DNA detection was performed via nested polymerase chain reaction (PCR), targeting the Leishmania ribosomal internal transcribed spacer 1 (ITS-1) described by el Tai et al. ${ }^{18}$ and Schönian et al. ${ }^{19}$ We used the inner primer set pair SAC/NAN2 to amplify an internal region (280 bp to $330 \mathrm{bp}$ ) with the methodology described by Cruz et al. ${ }^{20}$ To identify specific Leishmania spp., positive PCR products were purified and subjected to PCR-restriction fragment length polymorphism (PCR-RFLP), and the products were visualized in a $3 \%$ agarose gel. ${ }^{19}$ Direct sequencing of the positive PCR products was also performed by Sanger method with the CEQ 2000XL DNA Analysis System (Beckman Coulter, Inc., CA). The obtained sequences were analyzed and edited using BioEdit v7.2.5. 1999-2013 software (Tom Hall, Ibis Biosciences, Carlsbad, CA), and then compared in the GenBank ${ }^{\mathrm{TM}}$ database for species identification by BLASTn (Basic Local Alignment Search Tool; National Center for Biotechnology Information, U.S. National Library of Medicine, 8600 Rockville Pike, Bethesda MD; http://blast.ncbi.nlm.nih.gov/Blast.cgi).

Clinico-epidemiological and outcome variables. The outbreak description refers to the time of the diagnosis. The variables (age, gender, type of CL, treatment, and outcome) were recoded from the medical history of the dermatological dispensary.
Ethics statement. The project and all the protocols were reviewed and approved by the Research Department and Research Ethics Committee of the Hospital Dr. José Ramón Vidal, under the Ministry of Public Health (Corrientes Province).

Statistical analysis. Variables were entered onto an Excel spreadsheet, and data were analyzed with SPSS statistical software (version 22.0, SPSS Inc., Chicago, IL). Quantitative variables were compared using the Fisher exact test, and results yielding a $P$-value of less than 0.05 were considered statistically significant.

The location of cases per year within the municipalities of Corrientes and Riachuelo was determined using QGIS software version 3.4 Madeira (Open Source Geospatial Foundation; qgis.org/es/site/index.html). Using the GPS (WGS84), the previously geolocalized cases were imported and superimposed onto Google Maps (https://www.google.com/maps).

\section{RESULTS}

From May 1, 2015 to December 31, 2016, 80 cases of CL were diagnosed, plus one case of VL in a boy with skin lesions. Figure 1 presents the epidemiological curve of the outbreak. Diagnoses peaked in November $2015(n=22)$. Patients' median age was 33.6 years; $18.5 \%$ were younger than 15 years. The male:female ratio was 3.5:1 (Table 1). Of the six patients aged 65 years or older, just one (16.7\%) was a male; however, among the 75 people younger than 65 years, 62 (82.7\%) were men $(P<0.001)$.

Figure 2 shows the geographical distribution of cases. Fiftysix $(69.1 \%)$ patients lived in the municipality of Corrientes, 22 $(27.2 \%)$ in nearby Riachuelo, and three (3.7\%) in another province, although they worked in fisheries on an island of the Paraná River (Table 1). The incidence was 0.16 and 62.27 per 1,000 population in the study period in the municipalities of Corrientes and Riachuelo, respectively.

Of the 80 patients with CL, 55 had a single lesion, whereas the other 25 had multiple lesions (Table 1). There was no difference between age-groups or genders. None of the cases had mucocutaneous leishmaniasis.

Outcome and treatment data were available for 46 of the 81 patients. The clinical situation was serious enough to require

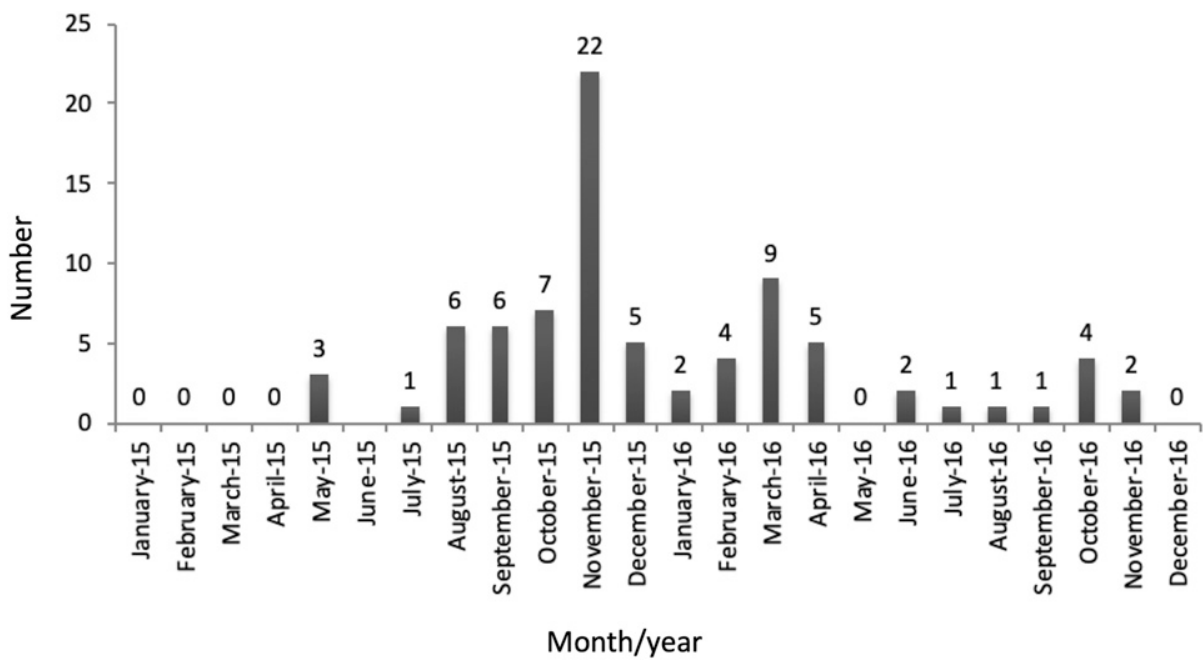

FIGURE 1. Epidemiological curve of leishmaniasis outbreak. 
TABLE 1

Epidemiological characteristics of leishmaniasis outbreak in Corrientes, Argentina (2015-2016)

\begin{tabular}{lc}
\hline \multicolumn{1}{c}{ Variable } & Participants $(N=81)$ \\
\hline Age (years), median (range) & $33.6(1-89)$ \\
Age-group (years), $n(\%)$ & \\
$0-14$ & $15(18.5)$ \\
$15-24$ & $18(22.2)$ \\
$25-34$ & $13(16.0)$ \\
$35-44$ & $12(14.8)$ \\
$45-64$ & $17(21.0)$ \\
$\geq 65$ & $6(7.4)$ \\
Gender, $n(\%)$ & $63(77.8)$ \\
Male & $18(22.2)$ \\
Female & \\
Municipality of residence, $n(\%)$ & $59(72.8 \%)$ \\
Corrientes ${ }^{*}$ & $22(27.2 \%)$ \\
Riachuelo & \\
Type of leishmaniasis, $n(\%)$ & $80(98.8)$ \\
Cutaneous leishmaniasis & $55(67.9)$ \\
$\quad$ Single lesion & $25(30.9)$ \\
Multiple lesions & $1(1.2)$ \\
Visceral leishmaniasis &
\end{tabular}

hospitalization in $23.8 \%$ (11/46). Most (82.6\%) were treated with glucantime and the rest with amphotericin B-deoxycholate. Data on treatment adherence were available for 41 patients; seven (17.5\%) did not complete their prescription (Table 2).

In all the cases, diagnosis was performed by direct observation of amastigotes in the stained slide smears of aspirates. However, molecular identification was performed in 28 of the 81 cases (34.6\%), and Leishmania spp. were amplified in 24 of them $(85.7 \%$ ) (Figure $3 \mathrm{~A}$ and B). Digestion with the restriction endonuclease Haelll of the amplified ITS- 1 region showed a suggestive pattern compatible with $L$. infantum species (Figure $3 C$ ). In addition, direct sequencing of ITS- 1 amplicons showed that $L$. infantum was the causative species in all cases, with a $98-100 \%$ level of certainty.

\section{DISCUSSION}

The epidemiology of leishmaniasis and specifically of $\mathrm{CL}$ is changing worldwide. ${ }^{21}$ Although we performed a molecular study in just a third of the cases, $87.5 \%$ of these were positive for $L$. infantum. The identification of this species in $C L$ in Argentina is noteworthy, as until now it had caused only $\mathrm{LV},{ }^{14-16}$ whereas $\mathrm{CL}$ was exclusively related to Leishmania braziliensis. ${ }^{6}$ Our study, therefore, signals a change in the northwestern region of Argentina, describing an outbreak of $C L$, caused for the first time by $L$. infantum.

In certain regions of Latin America, particularly in countries of Central America such as Honduras and Costa Rica and in the northern countries of South America, such as Venezuela, different reports have described cases of CL caused by $L$. infantum (chagasi) in immunocompetent patients. ${ }^{22-24}$ Likewise, two cases of $L$. infantum-caused $C L$ have been described in Paraguay, near the outbreak area discussed here. ${ }^{25,26}$

We can speculate on different factors that would influence the appearance of $C L$ because of $L$. infantum in the urban and periurban areas under study, including a high density of the vector, deficiencies in basic sanitary services (waste management and sanitation), deforestation, activities undermining vector control (inappropriate waste recycling and artisanal
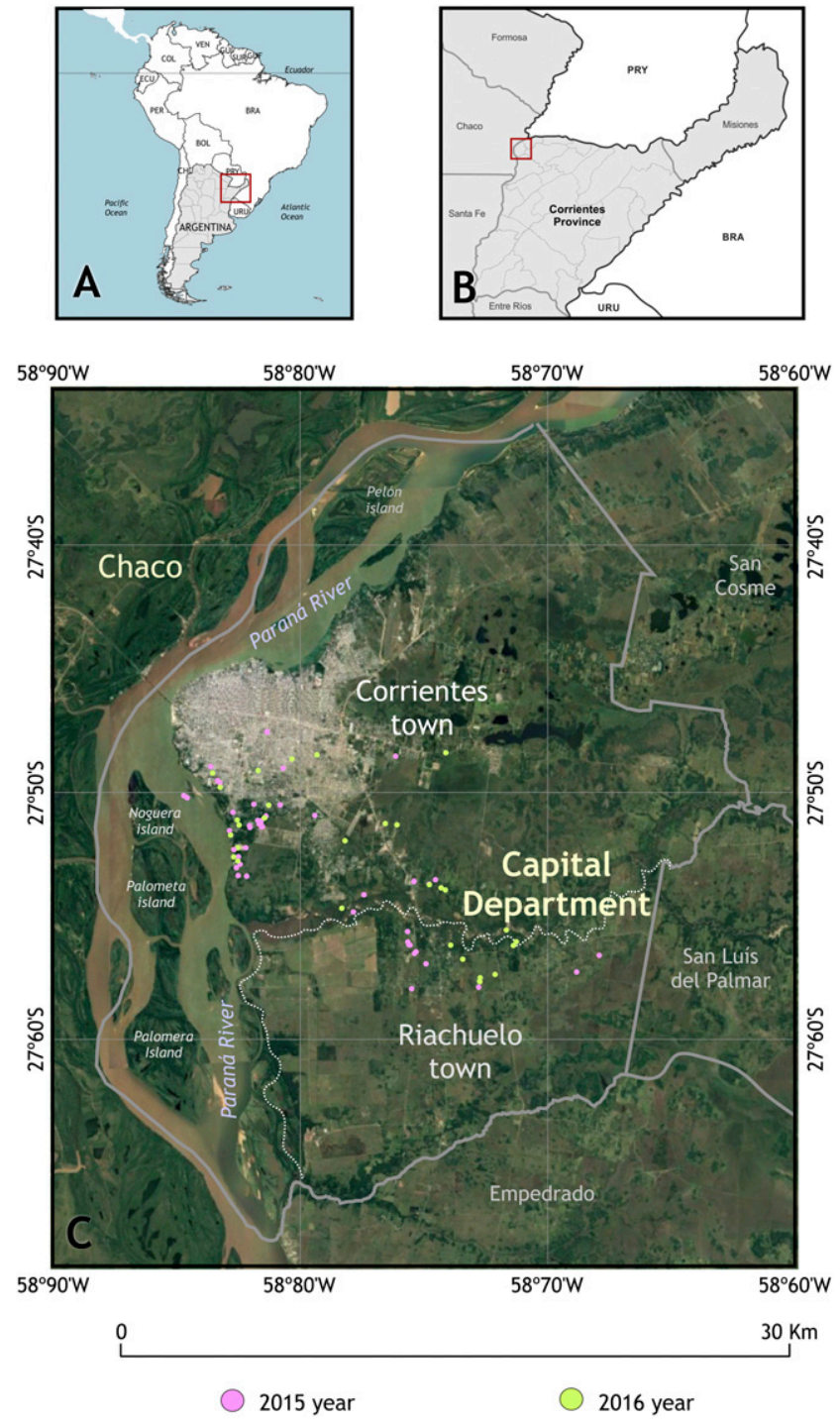

FIGURE 2. Location of cases in municipalities of Corrientes and Riachuelo, by year (light brown, 2015 and dark brown, 2016) in satellite version with forest in and around the city. This figure appears in color at www.ajtmh.org.

brickworks, among others), soil characteristics, the high concentration of families living in poverty and facing difficulties in accessing protection measures, and the presence of dogs infected by $L$. infantum in the area of study ${ }^{27-29}$ All of this multicausality could explain the occurrence of the first outbreak of this magnitude in a very dense urban and periurban area.

On the other hand, it is possible the molecular biology techniques necessary to diagnose this species of leishmania in $C L$ have simply been widely unavailable in this area of Argentina up to now. Indeed, it is likely that $L$. infantum has caused prior cases and outbreaks of CL, but diagnostic limitations precluded the identification of the species. That said, the molecular biology studies that have taken place in northwestern Argentina (in Salta) and in the province of Santiago del Estero have not identified this species. ${ }^{3,7,8}$

Our analysis suggests an urbanization of $\mathrm{CL}$, which is consistent with similar clinical and epidemiological patterns observed in the Mediterranean basin, ${ }^{30,31}$ and the presence of 
TABLE 2

Treatment and outcome

\begin{tabular}{lr}
\hline \multicolumn{1}{c}{ Variable } & $n / N$ exposed (\%) \\
\hline Treatment & \\
Glucantime & $38 / 46(28.6)$ \\
Amphotericin B-deoxycholate & $8 / 46(17.4)$ \\
Completed treatment & $33 / 41(82.5)$ \\
Hospitalization & $11 / 46(23.9)$ \\
Cured & $46 / 46(100)$ \\
\hline
\end{tabular}

good transmission vectors and high prevalence of canine infection, which facilitate the spread of the disease. ${ }^{28,29}$ These circumstances could herald a much greater impact and magnitude of $C L$ in the region in the near-to-medium term.

The main limitation of this study was that we were able to conduct a search for the parasite in only one of the samples, out of all of the cases diagnosed, because of the unavailability of slices.

In conclusion, $\mathrm{CL}$ is a growing public health problem in northern Argentina, and data from this outbreak reveal $L$. infantum as the responsible species. There is a need for
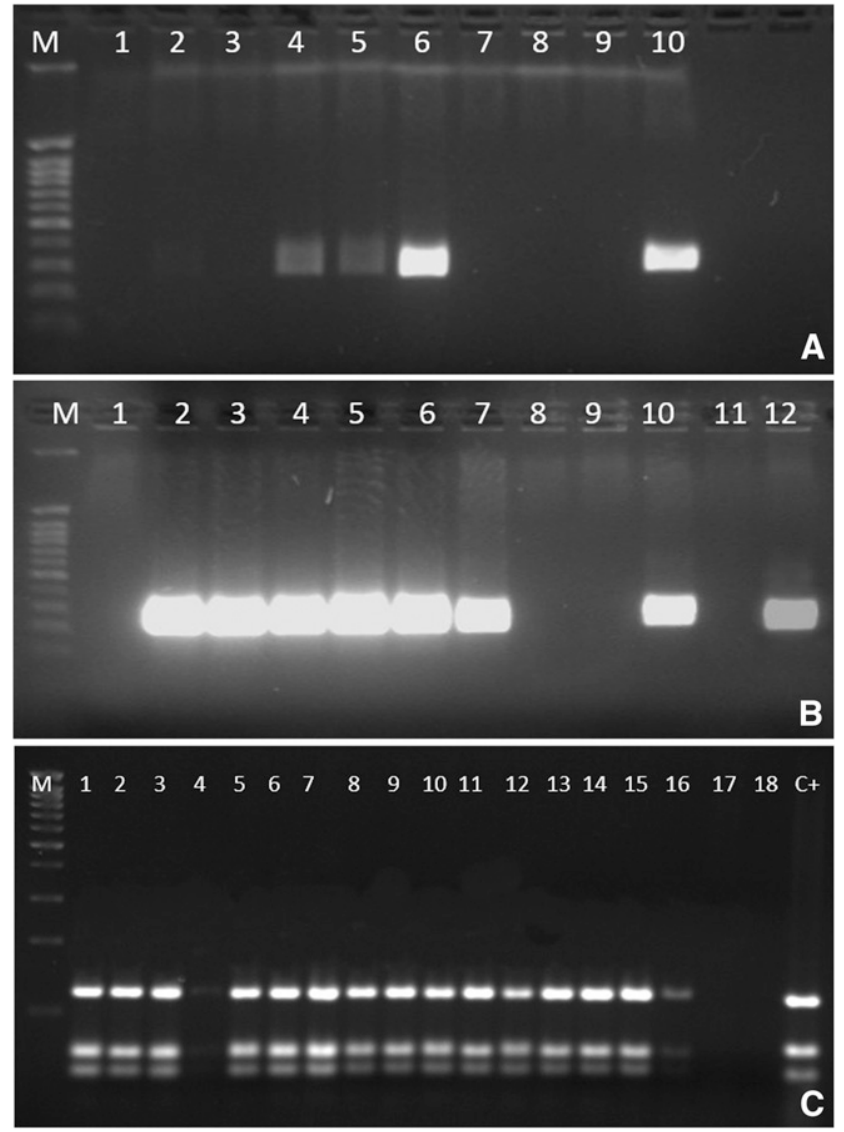

FIGURE 3. Leishmania-nested polymerase chain reaction (PCR) assays that amplified (A) first reaction with primers LITSR and L5.8S; M: molecular size marker; lanes 1 and 9: PCR-negative control, lines 2-7: clinical samples, line 8: extraction control, and line 10: first reaction positive control (300-350 bp). (B) Second reaction with inner primes SAC and VAN2 (Cruz et al., 2013); M: molecular size marker; lanes 1 and 9: PCR-negative control, lines 2-7: clinical samples; line 8: extraction control; line 10: first reaction positive control; line 11: second reaction negative control; and line 12: second reaction positive control (380-330 bp). (C) M: molecular size marker; lines 2-18: clinical samples; C+: Leishmania infantum-positive control. comprehensive control strategies that address this multicausal clinical and epidemiological situation in the region. Special attention should be paid to optimizing surveillance and improving environmental measures for vector control. Other actions include investigation of non-canine reservoirs, implemention of health education, and personal protection measures for the population.

Received July 16, 2019. Accepted for publication December 12, 2019. Acknowledgment: We would like to thank Meggan Harris for her technical support.

Authors' addresses: Lucrecia Acosta-Soto and Fernando-Jorge Bornay-Llinares, Parasitology Area, Universidad Miguel Hernández de Elche, Alicante, Spain, E-mails: lacosta@umh.es and f.bornay@ umh.es. Ernesto Sebastian Encinas, Clinical Bacteriology Service, Hospital Angela Llano, E-mail: sebaencinas@hotmail.com. EnriqueJorge Deschutter, Microbiology Department, Facultad de Ciencias Exactas, Químicas y Naturales de la Universidad Nacional de Misiones, Misiones, Argentina, E-mail: jorgedeschu@hotmail.com. RoqueAntonio-Luis Pasetto and Elisa-Maria-Angela Petri-de-Odriozola, Dispensario Dermatologico Hersilia Casares de Blaquier, E-mails: ralpasetto@hotmail.com and elisapetri@hotmail.com. José-Manuel Ramos-Rincón, Clinical Medicine Department, Universidad Miguel Hernández de Elche, Alicante, Spain, E-mails: jose.ramosr@goumh. umh.es or jose.ramos@umh.es.

\section{REFERENCES}

1. Karimkhani C, Wanga V, Coffeng LE, Naghavi P, Dellavalle RP, Naghavi M, 2016. Global burden of cutaneous leishmaniasis: a cross-sectional analysis from the Global Burden of Disease Study 2013. Lancet Infect Dis 16: 584-591.

2. Salomon O, Sinagra A, Nevot M, Barberian G, Paulin P, Estevez J, Riarte A, Estevez J, 2008. First visceral leishmaniasis focus in Argentina. Mem Inst Oswaldo Cruz 103: 109-111.

3. García Bustos MF et al., 2016. Clinical and epidemiological features of leishmaniasis in Northwestern-Argentina through a retrospective analysis of recent cases. Acta Trop 154: 125-132.

4. Salomón OD, Acardi SA, Liotta DJ, Fernández MS, Lestani E, López D, Mastrángelo AV, Figueroa M, Fattore G, 2009. Epidemiological aspects of cutaneous leishmaniasis in the Iguazú falls area of Argentina. Acta Trop 109: 5-11.

5. Salomón OD, Quintana MG, Mastrángelo AV, Fernández MS, 2012. Leishmaniasis and climate change-case study: Argentina. J Trop Med 2012: 601242.

6. Marco JD et al., 2005. Species assignation of Leishmania from human and canine American tegumentary leishmaniasis cases by multilocus enzyme electrophoresis in North Argentina. Am J Trop Med Hyg 72: 606-611.

7. Cuba CA, Torno CO, Ledesma O, Visciarelli E, Garcia S, Prat MI, Costamagna R, Barbieri L, Evans DA, 1996. Human cutaneous leishmaniasis caused by Leishmania (Viannia) braziliensis in Santiago del Estero, Argentina: identification of parasites by monoclonal antibodies and isoenzymes. Rev Inst Med Trop Sao Paulo 38: 413-421.

8. Segura EL, Juan N, Piquin AL, Cuba Cuba CA, Abramo Orrego L, McMahon-Pratt D, Montamat EE, Momen H, Grimaldi G Jr., 2000. Molecular and biologic characterization of Leishmania parasites implicated in an epidemic outbreak in northwestern Argentina. Parasitol Res 86: 504-508.

9. Lanús EC, Piñero JE, González AC, Valladares B, de Grosso ML, Salomón OD, 2005. Detection of Leishmania braziliensis in human paraffin-embedded tissues from Tucumán, Argentina by polymerase chain reaction. Mem Inst Oswaldo Cruz 100: 187-192.

10. Marco JD et al., 2012. Polymorphism-specific PCR enhances the diagnostic performance of American tegumentary leishmaniasis and allows the rapid identification of Leishmania species from Argentina. BMC Infect Dis 12: 191.

11. Acardi SA, Liotta DJ, Santini MS, Romagosa CM, Salomón OD, 2010. Detection of Leishmania infantum in naturally infected Lutzomyia longipalpis (Diptera: Psychodidae: Phlebotominae) 
and Canis familiaris in Misiones, Argentina: the first report of a PCR-RFLP and sequencing-based confirmation assay. Mem Inst Oswaldo Cruz 105: 796-799.

12. Acosta L, Díaz R, Torres P, Silva G, Ramos M, Fattore G, Deschutter EJ, Bornay-Llinares FJ, 2015. Identification of Leishmania infantum in Puerto lguazú, Misiones, Argentina. Rev Inst Med Trop Sao Paulo 57: 175-176.

13. Díaz RG, Salvatierra KA, Silva GA, Deschutter EJ, Bornay-Llinares FJ, Acosta L, 2019. Primera caracterización molecular de Leishmania infantum en pacientes con leishmaniosis visceral de la provincia de Misiones, Argentina. Biomedica 39: 405-414.

14. Barroso PA et al., 2015. Visceral leishmaniasis caused by Leishmania Infantum in Salta, Argentina: possible reservoirs and vectors. Am J Trop Med Hyg 93: 334-339.

15. Locatelli FM et al., 2014. The isolation and molecular characterization of Leishmania spp. from patients with American tegumentary leishmaniasis in northwest Argentina. Acta Trop 131: 16-21.

16. López K, Tartaglino LC, Steinhorst II., Santini MS, Salomon OD, 2016. Factores de riesgo en escenarios emergentes de leishmaniasis visceral urbana, Misiones, Argentina. Biomédica 36: 51-63.

17. Almazán MC et al., 2018. Molecular identification of Leishmania spp. DNA from Archived Giemsa-stained slides of patients from Salta, Argentina. Am J Trop Med Hyg 99: 1156-1161.

18. el Tai NO, Osman OF, el Fari M, Presber W, Schönian G, 2000. Genetic heterogeneity of ribosomal internal transcribed spacer in clinical samples of Leishmania donovani spotted on filter paper as revealed by single-strand conformation polymorphisms and sequencing. Trans R Soc Trop Med Hyg 94: 575-579.

19. Schönian G, Nasereddin A, Dinse N, Schweynoch C, Schallig HD, Presber W, Jaffe CL, 2003. PCR diagnosis and characterization of Leishmania in local and imported clinical samples. Diagn Microbiol Infect Dis 47: 349-358.

20. Cruz I et al., 2014. An approach for interlaboratory comparison of conventional and real-time PCR assays for diagnosis of human leishmaniasis. Exp Parasitol 134: 281-289.

21. Savić S, Vidić B, Grgić Z, Potkonjak ASL, 2014. Emerging vectorborne diseases - incidence through vectors. Front Public Heal 2: 267.
22. Zeledón R, Hidalgo H, Víquez A, Urbina A, 1997. Atypical cutaneous leishmaniasis in a semiarid region of north-west Costa Rica. Trans R Soc Trop Med Hyg 83: 786.

23. Noyes H, Chance M, Ponce C, Ponce E, Maingon R, 1997. Leishmania chagasi: genotypically similar parasites from Honduras cause both visceral and cutaneous leishmaniasis in humans. Exp Parasitol 85: 264-273.

24. De Lima H, Rodríguez N, Feliciangeli MD, Barrios MA, Sosa A, Agrela I, Sánchez E, Lopez O, 2009. Cutaneous leishmaniasis due to Leishmania chagasi/Le. infantum in an endemic area of Guarico State, Venezuela. Trans R Soc Trop Med Hyg 103: 721-726.

25. Aldama A et al., 2013. Leishmaniasis cutánea atípica por L. Infantum (chagasi). Fac Cienc Med (Asunción) 46: 61-67.

26. Chena L et al., 2015.Reporte de un caso de leishmaniosis cutánea causada por Leishmania infantum. Gac Dermatol (Asunción) 1: 13.

27. Salomón OD, Mastrángelo AV, Santini MS, Liotta DJ, Yadón ZE, 2016. Retrospective eco-epidemiology as a tool for the surveillance of leishmaniasis in Misiones, Argentina, 1920-2014 [article in Spanish]. Rev Panam Salud Publica 40: 29-39.

28. Berrozpe PE, Lamattina D, Santini MS, Araujo AV, Torrusio SE, Salomón OD, 2019. Spatiotemporal dynamics of Lutzomyia longipalpis and macro-habitat characterization using satellite images in a leishmaniasis-endemic city in Argentina. Med Vet Entomol 33: 89-98.

29. Ascencio ME, Sarmiento NF, Schnittger L, Florin-Christensen M, Rodriguez AE, 2019. Molecular diagnosis of Leishmania spp. in dogs of a subtropical locality of Argentina. Transbound Emerg Dis. doi: $10.1111 /$ tbed.13313.

30. Chicharro C, Llanes-Acevedo I, García E, Nieto J, Moreno J, Cruz I, 2013. Molecular typing of Leishmania infantum isolates from a leishmaniasis outbreak in Madrid, Spain, 2009 to 2012. Euro surveill 18: 20545.

31. Mubayi A, Paredes M, Ospina J, 2018. A comparative assessment of epidemiologically different cutaneous leishmaniasis outbreaks in Madrid, Spain and Tolima, Colombia: an estimation of the reproduction number via a mathematical model. Trop Med Infect Dis 3: E43. 